Kai I. Müller, MD

Karl B. Alstadhaug, MD, $\mathrm{PhD}$

Svein I. Bekkelund, MD, $\mathrm{PhD}$

Correspondence to

Dr. Müller:

kai.ivar.muller@unn.no
Supplemental data at Neurology.org

\title{
A randomized trial of telemedicine efficacy and safety for nonacute headaches OPEN
}

\section{ABSTRACT}

Objective: To evaluate long-term treatment efficacy and safety of one-time telemedicine consultations for nonacute headaches.

Methods: We randomized, allocated, and consulted nonacute headache patients via telemedicine $(n=200)$ or in a traditional manner $(n=202)$ in a noninferiority trial. Efficacy endpoints, assessed by questionnaires at 3 and 12 months, included change from baseline in Headache Impact Test- 6 (HIT-6) (primary endpoint) and pain intensity (visual analogue scale [VAS]) (secondary endpoint). The primary safety endpoint, assessed via patient records, was presence of secondary headache within 12 months after consultation.

Results: We found no differences between telemedicine and traditional consultations in HIT-6 $(p=0.84)$ or VAS $(p=0.64)$ over 3 periods. The absolute difference in HIT- 6 from baseline was 0.3 (95\% confidence interval [Cl] -1.26 to $1.82, p=0.72)$ at 3 months and $0.2(95 \% \mathrm{Cl}$ -1.98 to $1.58, p=0.83)$ at 12 months. The absolute change in VAS was $0.4(95 \% \mathrm{Cl}-0.93$ to $0.22, p=0.23)$ after 3 months and $0.3(95 \% \mathrm{Cl}-0.94$ to $0.29, p=0.30)$ at 12 months. We found one secondary headache in each group at 12 months. The estimated number of consultations needed to miss one secondary headache with the use of telemedicine was 20,200 .

Conclusion: Telemedicine consultation for nonacute headache is as efficient and safe as a traditional consultation.

\section{ClinicalTrials.gov identifier: NCT02270177}

Classification of evidence: This study provides Class III evidence that a one-time telemedicine consultation for nonacute headache is noninferior to a one-time traditional consultation regarding long-term treatment outcome and safety. Neurology ${ }^{\circledR}$ 2017;89:153-162

\section{GLOSSARY}

ANOVA = analysis of variance; $\mathbf{C l}=$ confidence interval; FLAIR = fluid-attenuated inversion recovery; HIT-6 = Headache Impact Test-6; VAS = visual analogue scale.

Headaches are widespread, and will be experienced by most people. ${ }^{1}$ According to the Global Burden of Disease, tension-type headache and migraine are the second and fourth most prevalent disorders in the world. Together with medication overuse headache, they are the 3 most prevalent neurologic disorders. ${ }^{2}$ Headaches may seem trivial, but many seek health care for headache-related disability. ${ }^{3}$

The geographic area of Northern Norway is huge, and broken up by mountains, valleys, and fjords into many sparsely populated places (figure e-1 at Neurology.org). Cumbersome and expensive travel hampers access to care for many headache sufferers.

We evaluated long-term treatment outcomes and safety of telemedicine consultations for nonacute headaches in a secondary neurologic outpatient department. The primary hypothesis

\footnotetext{
From the Department of Clinical Medicine (K.I.M., K.B.A., S.I.B.), UiT-The Arctic University of Norway; Department of Neurology (K.I.M., S.I.B.), University Hospital of North Norway, Tromsø; and Department of Neurology (K.B.A.), Nordland Hospital Trust, Bodø, Norway.

Go to Neurology.org for full disclosures. Funding information and disclosures deemed relevant by the authors, if any, are provided at the end of the article. The Article Processing Charge was funded by grants from Helse Nord RHF (The Northern Norway Regional Health Authority).

This is an open access article distributed under the terms of the Creative Commons Attribution-NonCommercial-NoDerivatives License 4.0 (CC BY-NC-ND), which permits downloading and sharing the work provided it is properly cited. The work cannot be changed in any way or used commercially without permission from the journal.
} 
was that telemedicine consultations are noninferior to traditional consultations in treatment and safety at 12 months.

METHODS Trial design. We conducted this noninferiority trial at the department of Neurology in Tromsø University Hospital in Norway (figure e-1).

Power was calculated on the assumption of a normal distribution of a primary binary satisfaction variable with an inferiority limit of $15 \%$. With an $\alpha$ of 0.01 in a $98 \%$ confidence interval (CI), 127 participants in each group were required to reach a power of $95 \%$.

In the area of coverage, access to all patient records in Northern Norway is made possible by a shared database in the
Distributed Information and Patient System for hospitals (DIPS ASA, Bodø, Norway). ${ }^{4}$

From September 30, 2012, until March 30, 2015, we consecutively screened and recruited 402 (to ensure applicable 12month data) out of 557 headache patients (figure 1). We included Norwegian-speaking female and male participants aged 16-65 years referred from primary care to a neurologist for headache management with a maximum 4 months waiting time from date of referral. Patients who underwent a neurologic headache consultation within the last 2 years were excluded. We defined headache as nonacute, and less likely secondary, if it started gradually, occurred at least 4 weeks prior to referral, and showed no clinical or radiologic abnormalities. ${ }^{5,6}$ Findings from the clinical neurologic examination and neuroimaging performed as part of the

Figure 1 Flow of participants through the study

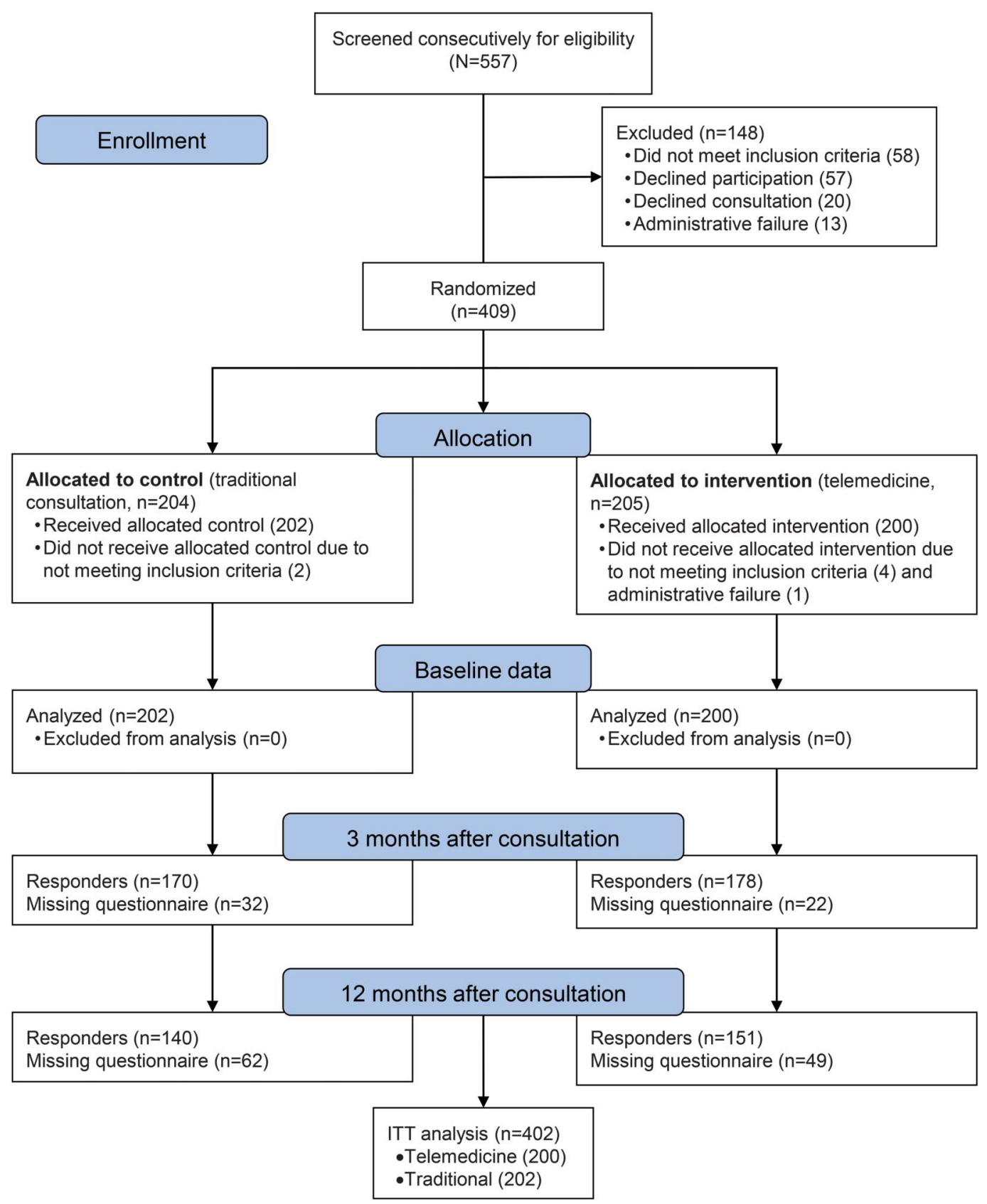

$\mathrm{ITT}=$ intention-to-treat. 
primary clinical evaluation were regarded as sufficient supplementary information to perform a realistic safety investigation.

All participants received written study information and filled out social and demographic questionnaires, Headache Impact Test-6 (HIT-6), ${ }^{7}$ visual analogue pain scale (VAS), ${ }^{8}$ and consent forms beforehand. At entrance, all participants came to the hospital in Tromsø and met at the patient reception in the neurologic department (figure e-1). A nurse controlled the patient's selfadministered forms and the consent, and phoned the external research department at the University Hospital for block randomization. Randomization was computer-generated by using an Rnd function in Microsoft (Redmond, WA) Access. Then, the nurse followed each participant either to a patient examination room at the department (traditional group) or to a videoconference room located next to the Department of Neurology (telemedicine group).

Patients in the traditional group were consulted in-person, face-to-face in the examination room at the Department of Neurology. The neurologists conducted telemedicine visits via a Cisco (Moorestown, NJ) EX60 unit from the examination rooms where the traditional consultations took place. The patient was then located remotely in the videoconference room. The videoconference room had a Cisco C40 integrator package installed providing a 2-way video and audio communication between the neurologist and the patient. The neurologists (K.I.M. and S.I.B.) checked the inclusion criteria, filled in the diagnostic checklist, performed a standardized interview without neurologic examinations, and completed the consultation.

Both the telemedicine and the traditional in-person consultation was a one-time consultation of new referred headache patients. In most cases, only the neurologist and the patient were present at consultation, but a relative or a friend accompanied a few.

Questionnaires and patient records. We sent a structured questionnaire by patient preference, either through an online survey service (Questback) or by mail at 3 and 12 months with a reminder after 2 weeks to the nonresponders. ${ }^{10}$

Participants were asked the following:

1. To complete the HIT- $6^{7}$

2. For the intensity of headache measured on VAS $^{8}$

3. To fill in number of headache days and headache attacks per month for the last 3 months

4. For the subjective change in headache frequency and intensity:

"Is the headache better, unchanged, or worse?" "Is the headache frequency reduced, unchanged, or increased?" "Is the headache intensity reduced, unchanged, or increased?"

5. For other disability measures, including employment, sick leave, and other social benefits

6. For the use of medication, including frequency of painkillers and triptans

7. Whether patients underwent brain neuroimaging with CT, MRI, or both within 12 months after consultation

8. For recall of the given headache diagnosis, compliance with given treatment, and number of general practitioner visits within the 12 months after the baseline consultation

9. For number of neurologic visits and hospitalizations for headaches within the 12 months after the baseline consultation

Outcome variables. Demographics were compared between telemedicine and traditional groups of all participants and those answering the 12-month questionnaire (table 1). Clinical and headache characteristics including comorbidity and diagnosis according to International Classification of Headache Disorders-2, ${ }^{11}$
HIT-6, and VAS of all the participants and those answering the 12month questionnaire were recorded (table 1).

Efficacy endpoints and general practitioner follow-up visits were evaluated through the questionnaires. Safety endpoints, neurologic follow-ups, and hospitalizations were reported by the participants in the 12-month questionnaire, but also validated by screening the patients' hospital records from the year passed since the baseline consultation.

The primary efficacy endpoint was a change in headache burden measured by HIT-6 across 3 periods (at consultation, at 3 months, and at 12 months). The HIT-6 is a patient-reported headache outcome measure that assesses the influence of headache on daily life. It consists of 6 headache questions relating to daily activities and work, pain, fatigue, and irritability. Every question has 5 answers (never, rarely, sometimes, very often, and always), and each answer scores $6,8,10,11$, or 13 points, respectively. A score above 56 has substantial influence on daily life.

The primary safety outcome was incidents of secondary headaches revealed within 12 months after the headache specialist consultation.

The main secondary efficacy endpoint was a change in headache intensity measured on VAS across 3 periods (at consultation, at 3 months, and at 12 months). The horizontal VAS scale from 0 to $10,0=$ no pain, $10=$ worst possible pain, is valid and reliable for assessing headache intensity and many other pain conditions. ${ }^{8}$ Other secondary efficacy outcome measures were change in work status, sick leave, perception of headache, headache days per month over the last 3 months, frequency of painkillers, triptans, and headache prophylactics in the last month, and diagnostic recall at 12 months. The use of painkillers and triptans were divided into 4 groups: $>3$ days a week, $1-2$ days a week, $<1$ day a week but $>$ every second week, and $<1$ day every second week.

Secondary safety outcomes were assessed by findings of pathology on brain neuroimaging requisitioned at the specialist consultation. The frequency of headache-related hospitalizations and specialist headache visits within 12 months after the specialist consultation were assessed to evaluate the quality and safety of telemedicine. $^{12}$

Other secondary safety outcomes were compliance with treatment and abnormal CSF analysis demonstrated within 12 months after the specialist headache consultation.

Participants were brain scanned in CT or in 1.5T MRI machines. The CT was performed by a spiral technique with reconstructions in 3 planes (coronal, sagittal, and axial). All MRIs had a Head/SENSE-Head/Flex-L coil and included at least the following sequences: sagittal 3D fluid-attenuated inversion recovery (FLAIR), axial T2 turbo spin echo $4 \mathrm{~mm}$, axial T2 fast field echo $4 \mathrm{~mm}$, axial diffusion $4 \mathrm{~mm}$, and sagittal T1 spin echo $5.5 \mathrm{~mm}$. All neuroimages were evaluated either by experienced radiologists or with a second opinion from neuroradiologists.

Neuroimaging findings were classified as being normal, nonsignificant, or significant. ${ }^{13,14}$ Normal was defined as no abnormalities or white matter hyperintensities (T2/FLAIR) corresponding to $\leq 1$ on the Fazekas scale, nonsignificant as abnormalities not influencing further management or Fazekas scale $>1$, and significant if abnormalities needed follow-up treatment or were categorized as clinically significant neurologic findings according to given criteria. ${ }^{13,15}$

Statistical methods. Data were analyzed with SPSS (Armonk, NY) 23. To ascertain normality, we inspected continuous variables by histogram and calculated kurtosis and skewness before performing independent-samples $t$ tests. Categorical variables were compared 
Table 1 Baseline demographics and clinical characteristics of the randomized groups in patients referred to a specialist for headache

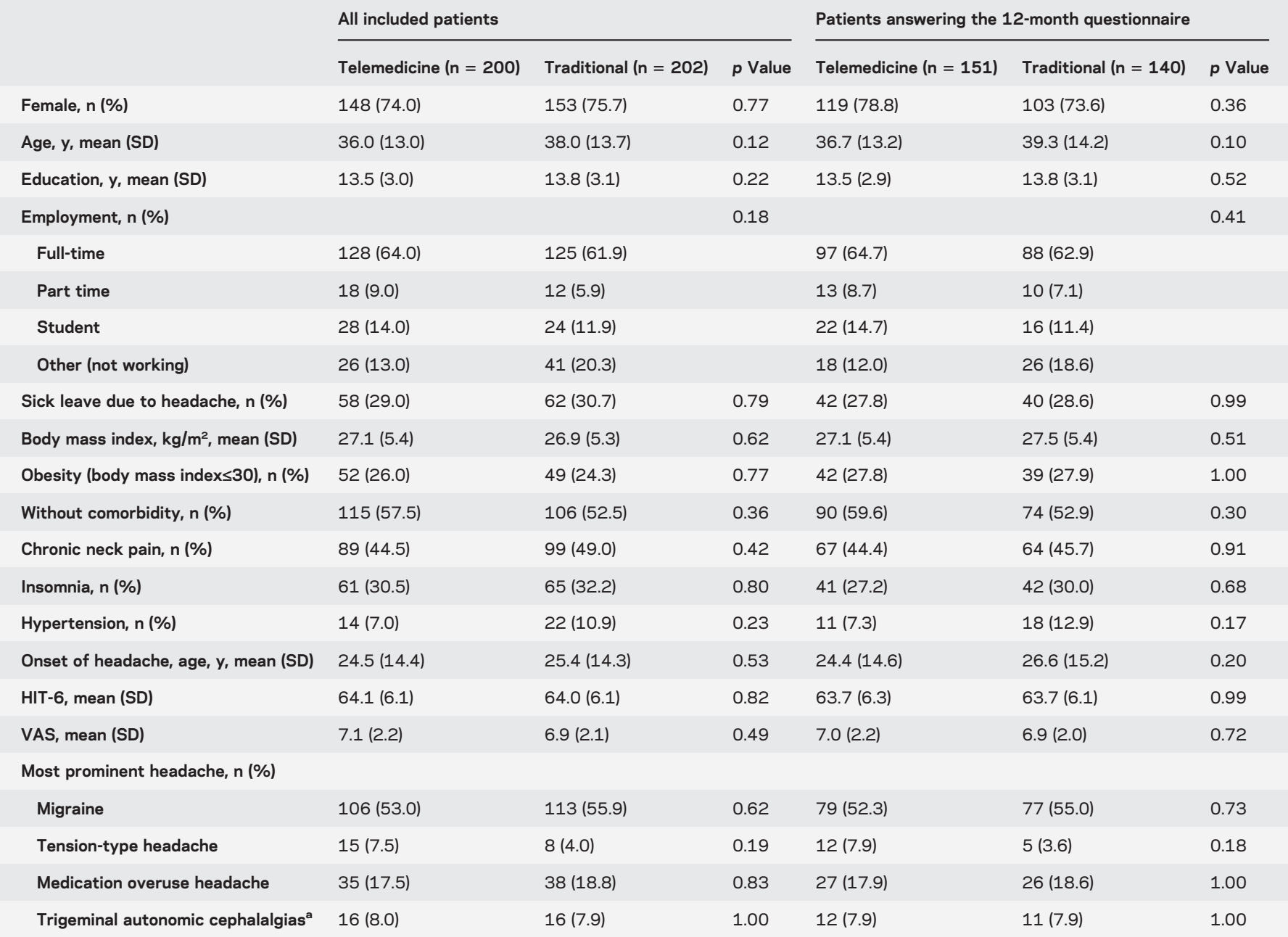

Abbreviations: HIT-6 = Headache Impact Test-6; VAS = visual analogue scale.

The first 3 columns correspond to all included patients. The last 3 columns correspond to those who answered the 12-month questionnaire.

a Cluster headache, paroxysmal hemicrania, and hemicrania continua.

using $\chi^{2}$ test and presented as numbers and percentages. All tests were 2 -sided. Statistical significance was set at $p<0.05$. Intention-to-treat analysis was performed by using last observed value carrying forward for continuous variables together with cross-tabulation with missing values for categorical variables. Variables not prespecified are labeled in Results. We used mixed between-within participants analysis of variance (ANOVA) to assess whether change in HIT- 6 and VAS differed between telemedicine and traditional consultations across 3 time periods. These results were presented as Wilks $\lambda$, partial $\eta^{2}$, and $F$ score. Absolute results and numbers needed to treat/harm were calculated for the primary and main secondary outcome measures.

Consent, registration, and ethical approval. We received oral and written consent from all participants before data collection. The Norwegian National Committee for Medical and Health Research Ethics approved the study (2009/1430/REK), and it conforms with the Helsinki Declaration. ${ }^{16}$ The trial was registered at the Norwegian Research and Management database (FAS ID3897/HST959-10) and retrospectively at ClinicalTrials.gov (NCT02270177). ${ }^{17}$

RESULTS The 3-month questionnaire was answered by $348 / 402$ (86.6\%), and 291/402
(72.4\%) answered the 12-month questionnaire. HIT-6 Cronbach $\alpha$ coefficients were $0.84,0.89$, and 0.90 at baseline and 3 and 12 months, respectively. Feasibility outcomes, 3-month followup data, and recommended interventions are published elsewhere. ${ }^{9,18}$

Mixed between-within participants ANOVA with a significance level of 0.05 and $95 \%$ CIs showed no differences in HIT-6 or VAS between the telemedicine and the traditional group over 3 periods: $F_{1,271}=0.043, p=0.84$, and $F_{1,255}=$ $0.22, p=0.64$, for HIT-6 and VAS, respectively (figure 2).

The absolute changes in HIT-6 were $0.3(95 \%$ CI -1.26 to $1.82, p=0.72)$ at 3 months and 0.2 (95\% CI -1.98 to $1.58, p=0.83$ ) at 12 months. The absolute changes in VAS were 0.4 (95\% CI -0.93 to $0.22, p=0.23)$ at 3 months and 0.3 (95\% CI -0.94 to $0.29, p=0.30$ ) at 12 months. Figure 2 compares the decline in HIT-6 and VAS 
Figure 2 Prespecified Headache Impact Test-6 (HIT-6) and visual analogue scale (VAS) from baseline to 12 months after consultation

A

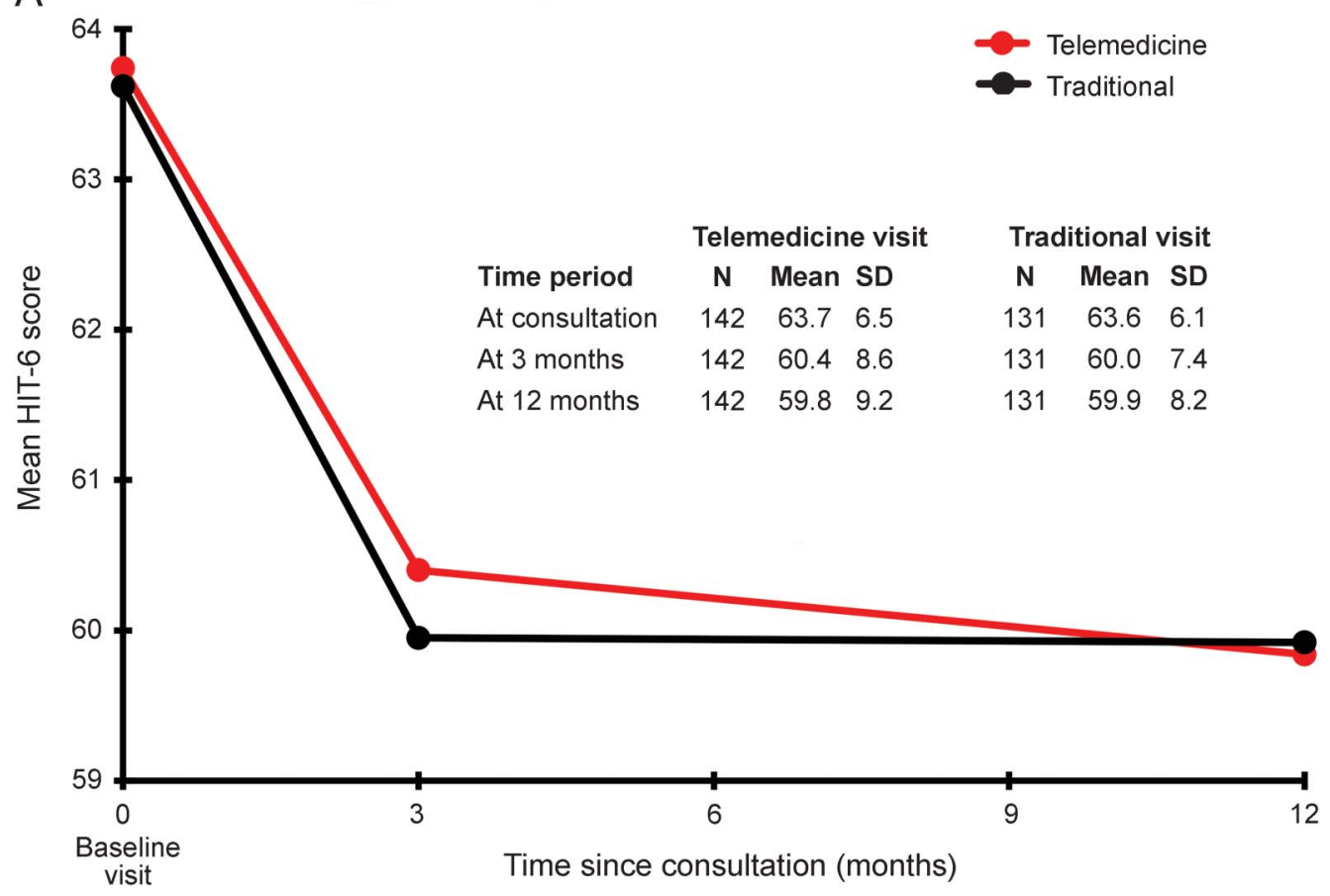

B

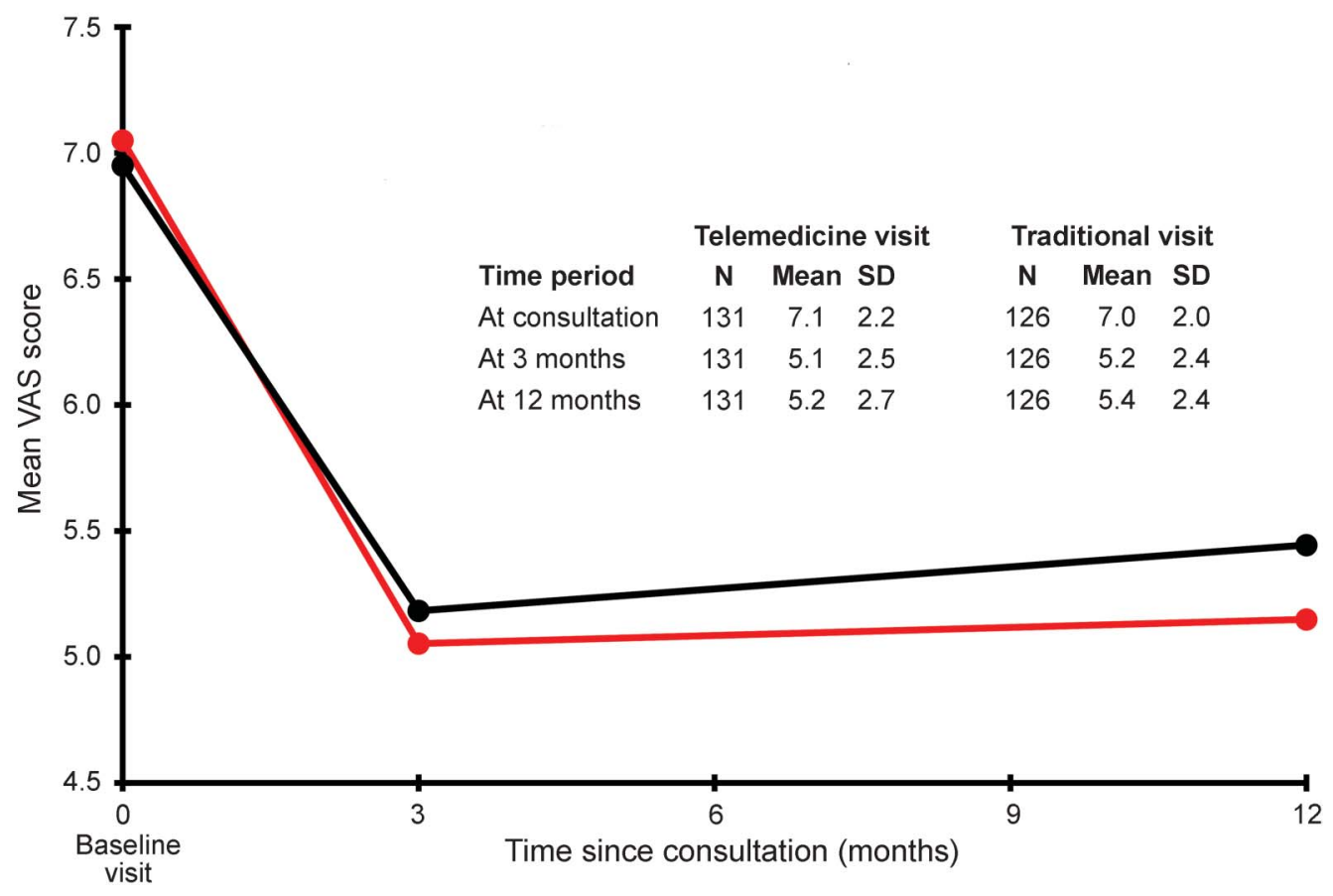

(A) HIT-6 ( $p=0.84)$ and (B) VAS $(p=0.64)$ from baseline to 12 months after consultation.

scores between telemedicine and traditional consultations across 3 periods.

Table 2 compares treatment efficiency variables between telemedicine and traditional headache consultations of patients who answered the 12-month questionnaire. Table 3 compares quality and safety variables between the 2 groups within 12 months after the consultation.

We identified one secondary headache in each group (table 3). The number of telemedicine consultations needed to miss one secondary headache was $1 /(1 / 202-1 / 200)=20,200(95 \% \mathrm{CI})$. 
Table 2 Treatment efficiency among patients 12 months after a specialist headache consultation ${ }^{\mathrm{a}, \mathrm{b}}$

\begin{tabular}{|c|c|c|c|}
\hline & $\begin{array}{l}\text { Telemedicine } \\
\text { ( } \mathrm{n}=151)\end{array}$ & $\begin{array}{l}\text { Traditional } \\
(n=140)\end{array}$ & $\begin{array}{l}\text { p Value } \\
\text { (95\% Cl) }\end{array}$ \\
\hline \multicolumn{4}{|l|}{ Work status, n (\%) } \\
\hline No change & $96(80.0)$ & $78(75.0)$ & 0.04 \\
\hline Off sick list & $18(15.0)$ & $11(10.6)$ & \\
\hline On sick list & $6(5.0)$ & $15(14.4)$ & \\
\hline Subjectively less headache, $n(\%)$ & $102(67.5)$ & $88(62.9)$ & 0.47 \\
\hline Subjectively unchanged, $\mathrm{n}(\%)$ & $36(23.8)$ & 34 (24.3) & 1.00 \\
\hline Subjectively more, n (\%) & $12(7.9)$ & $16(11.4)$ & 0.42 \\
\hline VAS, mean (SD) & $5.2(2.7)$ & $5.5(2.5)$ & $0.43(-0.36$ to 0.85$)$ \\
\hline$\Delta$ VAS, mean $(\mathrm{SD})^{\mathrm{c}, \mathrm{d}}$ & $-1.9(2.8)$ & $-1.5(2.4)$ & $0.30(-0.29$ to 0.94$)$ \\
\hline HIT-6, mean (SD) & $60.0(9.1)$ & $60.1(8.3)$ & $0.90(-1.90$ to 2.15$)$ \\
\hline$\Delta \mathrm{HIT}-6$, mean $(\mathrm{SD})^{\mathrm{c}, \mathrm{e}}$ & $-3.66(7.6)$ & $-3.46(7.7)$ & 0.83 (-1.98 to 1.58$)$ \\
\hline Headache days/mo, n (\%) & & & 0.74 \\
\hline$>15$ & $64(42.7)$ & $63(45.0)$ & \\
\hline $7-15$ & 47 (31.3) & $38(27.1)$ & \\
\hline$<7$ & $39(26.0)$ & 39 (27.9) & \\
\hline Frequency of painkillers use, $n$ (\%) & & & 0.33 \\
\hline$>3$ days/wk & 32 (23.2) & $43(32.8)$ & \\
\hline $1-2$ days/wk & $30(24.6)$ & $26(19.8)$ & \\
\hline$<1$ day/wk, but $>$ every 2 weeks & 34 (24.6) & $25(19.1)$ & \\
\hline$<1$ day every 2 weeks & $42(30.4)$ & 37 (28.2) & \\
\hline Frequency of triptan use, $n(\%)$ & & & 0.71 \\
\hline$>3$ days/wk & $8(9.9)$ & 8 (14.3) & \\
\hline $1-2$ days/wk & $21(25.9)$ & $15(26.8)$ & \\
\hline$<1$ day/wk, but $>$ every 2 weeks & $13(16.0)$ & 11 (19.6) & \\
\hline$<1$ day every 2 weeks & 39 (48.1) & 22 (39.3) & \\
\hline On prophylactic medication, n (\%) & $56(37.1)$ & $53(37.9)$ & 0.99 \\
\hline Recalled diagnosis, n (\%) & 111 (73.5) & $103(73.6)$ & 1.00 \\
\hline Did you have neuroimaging?, $n(\%)^{f}$ & & & 0.28 \\
\hline MRI & $80(55.2)$ & 75 (54.3) & \\
\hline CT & $13(9.0)$ & $6(4.3)$ & \\
\hline Both & 25 (17.2) & $33(23.9)$ & \\
\hline Specialist headache visits, $\mathrm{n}(\%)$ & 19 (13.4) & $22(16.8)$ & 0.54 \\
\hline No. of specialist visits, mean (SD) & $0.23(0.74)$ & $0.34(1.0)$ & 0.30 ( -0.98 to 0.32$)$ \\
\hline GP visits, n (\%) & $89(63.1)$ & $92(69.2)$ & 0.35 \\
\hline No. of GP visits, mean (SD) & 2.25 (3.2) & 2.95 (3.8) & $0.10(-0.12$ to 1.54$)$ \\
\hline
\end{tabular}

Abbreviations: $\mathrm{Cl}=$ confidence interval; GP $=$ general practitioner; HIT-6 = Headache Impact Test-6; VAS = visual analogue scale.

${ }^{\text {a }}$ Per protocol analyses of the 12-month questionnaire.

${ }^{b}$ All conclusions of intention-to-treat analyses coincided with per protocol analyses. $p$ Value of work status in intention-totreat $=0.03$.

${ }^{\mathrm{c}}$ The difference between 12-month follow-up and baseline data.

${ }^{\mathrm{d}} \mathrm{O}=$ No pain; $10=$ worst possible pain.

${ }^{e} \mathrm{~A} 6$-item patient-related outcome measure where a score above 50 is considered high.

${ }^{f}$ Nonprespecified variable. All other variables in the table are prespecified. 


\begin{tabular}{|c|c|c|c|c|}
\hline \multirow[t]{2}{*}{ Table 3} & \multicolumn{4}{|c|}{$\begin{array}{l}\text { Safety of specialist telemedicine consultations for nonacute } \\
\text { headaches }\end{array}$} \\
\hline & & $\begin{array}{l}\text { Telemedicine } \\
(\mathrm{n}=200)\end{array}$ & $\begin{array}{l}\text { Traditional } \\
(\mathrm{n}=202)\end{array}$ & $p$ Value \\
\hline \multicolumn{2}{|c|}{ Secondary headaches, n (\%) ${ }^{a}$} & $1(0.5)$ & $1(0.5)$ & NA \\
\hline \multicolumn{3}{|c|}{$\begin{array}{l}\text { Requisitioned brain imaging, } n \\
(\%)^{a}\end{array}$} & & 0.29 \\
\hline \multicolumn{2}{|l|}{ Normal } & $58(80.6)$ & 62 (89.9) & \\
\hline \multicolumn{2}{|c|}{ Not significant changes } & 8 (11.1) & $4(5.8)$ & \\
\hline \multicolumn{2}{|c|}{ Significant changes } & $6(8.3)$ & $3(4.3)$ & \\
\hline \multicolumn{2}{|c|}{ Abnormal ordered imagings, $n(\%)^{a}$} & $14(19.4)$ & $7(10.1)$ & 0.19 \\
\hline \multicolumn{2}{|c|}{ All abnormal brain imaging, $\mathrm{n}(\%)^{\mathrm{a}}$} & $24(13.7)$ & 20 (11.6) & 0.66 \\
\hline \multicolumn{2}{|c|}{ All brain imaging, $n(\%)^{a}$} & & & 0.67 \\
\hline \multicolumn{2}{|l|}{ Normal } & $151(86.3)$ & $153(88.4)$ & \\
\hline \multicolumn{2}{|c|}{ Not significant changes } & $12(6.9)$ & $8(4.6)$ & \\
\hline \multicolumn{2}{|c|}{ Significant changes } & $12(6.9)$ & $12(6.9)$ & \\
\hline \multicolumn{2}{|c|}{$\begin{array}{l}\text { Headache visits/hospitalizations, } \\
\text { mean (SD) }{ }^{b, c}\end{array}$} & $0.19(0.55)$ & $0.21(0.63)$ & 0.76 \\
\hline \multicolumn{2}{|c|}{ All hospitalizations, $n(\%)^{b}$} & & & 0.47 \\
\hline \multicolumn{2}{|l|}{ None } & $182(91.0)$ & $174(86.1)$ & \\
\hline \multicolumn{2}{|l|}{1} & $14(7.0)$ & 23 (11.4) & \\
\hline \multicolumn{2}{|l|}{2} & $3(1.5)$ & $4(2.0)$ & \\
\hline \multicolumn{2}{|l|}{3} & $1(0.5)$ & $1(0.5)$ & \\
\hline \multicolumn{2}{|c|}{ Compliance to treatment, $n(\%)^{\mathrm{a}, \mathrm{d}}$} & $100(73.5)$ & $86(71.1)$ & 0.76 \\
\hline \multicolumn{2}{|c|}{ Requisitioned LP, n (\%) ${ }^{a}$} & $8(4.0)$ & $11(5.4)$ & 0.65 \\
\hline
\end{tabular}

Abbreviations: $\mathrm{LP}=$ lumbar puncture; NA = not applicable.

a Nonprespecified analyses.

${ }^{\mathrm{b}}$ Prespecified frequency at 12 months due to headache.

c $95 \%$ Confidence interval -0.13 to 0.10 .

${ }^{\mathrm{d}}$ No. $=151$ in the telemedicine and 140 in the traditional group. Compliance with treatment is from the 12-month questionnaire. The other variables are from the electronic patient records.

Reasons for hospitalizations due to headache were as follows:

Telemedicine:

1. Endovascular stenting of an extracranial vertebral artery. The tension-type headache subsided after treatment. This was the patient with secondary headache.

2. Clips on a middle cerebral artery aneurysm. No change in cluster headache on 12-month followup after neurosurgery.

3. A patient with orgasmic headache was admitted to evaluate vasospasms with CT angiography and lumbar puncture. She was treated with nifedipine. CT angiography was normal 3 months later.

4. Treatment of postdural puncture headache.

5. A patient was hospitalized twice for status migrainosus.

6. X-ray-guided lumbar puncture and medication withdrawal due to medication overuse headache.

7. Medication withdrawal due to medication overuse headache.
Traditional:

1. A patient with migraine and medication overuse headache was hospitalized after a second opinion neuroradiologic interpretation of brain MRI suggesting idiopathic intracranial hypertension, which was later confirmed. This was the patient with secondary headache.

2. A patient with cluster headache admitted to test inhalation of $100 \%$ oxygen as attack-aborting treatment.

3. Treatment of postdural puncture headache.

4. Neuropsychological testing of a patient with migraine due to subjective cognitive decline. The test was normal.

The significant neuroimaging findings in the telemedicine group included a middle cerebral artery aneurysm (1 patient), vasospasms (1 patient), white matter damage of suspected prenatal origin (2 patients), 1 ArnoldChiari malformation type 1 , and 1 benign tumor in the masseter muscle. In the traditional group, 2 patients had meningioma, and 1 had a Dandy-Walker anomaly. None of the above-mentioned findings was associated with the headaches diagnosed at the consultation.

All 19 lumbar punctures, except in the patient with idiopathic intracranial hypertension, had normal CSF opening pressure, and all had normal leucocyte, protein, and isoelectric focusing.

DISCUSSION With similar conditions in telemedicine and traditional headache consultations of new patients recruited consecutively from our neurologic outpatient department, we found no significant differences in long-term treatment efficacy measured repeatedly with HIT-6 and VAS over 12 months. By thoroughly rereading every participant's hospital patient records, 1 secondary headache was identified in each group within the first year after the headache consultation, and findings on neuroimaging were equally distributed between the 2 randomized groups. Further evaluation after 1 year showed that headache patients consulted through telemedicine were followed up in a similar manner as those who underwent traditional consultations. With no significant differences between the 2 methods of consultation, telemedicine is as efficient and safe as traditional visits in long-term treatment outcome of nonacute headaches.

There are a few randomized controlled 2-way visual and audio telemedicine trials of neurologic conditions beyond stroke. ${ }^{19-21}$ Other randomized studies are based on treatment of already diagnosed conditions. ${ }^{22-24}$ Still, telemedicine is widely used in neurologic departments as well as for headache management. ${ }^{12,25,26}$ Our study shows that after 12 months of follow-up, headache burden, subjective and objective headache change, or treatment follow-up 
outcomes are not statistically in favor of traditional visits (figure 2 and table 2). The long-term similar outcomes of both groups adds to the cost-saving analysis in our previous article. ${ }^{9}$ In a cost-minimization perspective, we now evaluate these results as strongly indicating cost-effectiveness for telemedicine. ${ }^{9}$ This randomized trial will help to build a base of evidence for telemedicine consultations for nonacute headaches, and prevent making it less safe than it has to be.

The list of differential diagnoses of headaches is one of the longest in medicine, but fortunately, secondary headaches caused by structural brain disorders are rare. ${ }^{27}$ However, some secondary headaches may be life-threatening, and physicians often struggle to see the forest for the trees. ${ }^{6}$ Some neurologists in Norway require MRI before a patient with nonacute headache is referred, and this is also the case in the United States. ${ }^{28}$ During a headache consultation, physicians should aim at identifying warning signs for secondary causes of headache. ${ }^{6}$

By excluding secondary headaches from the referrals as performed in clinical practice, the risk of missing secondary headaches due to misdiagnosis was small. After 12 months, the frequency of secondary headaches, brain neuroimaging pathology, hospital stays due to misdiagnoses or headache-related treatment, as well as compliance and lumbar puncture results were comparable between the groups. Although we applied the same classification criteria as a population-based study, there were less significant findings on the brain imagings. ${ }^{13}$ One reason may be that we initially excluded secondary headaches, but patients in our study were also younger. The present study documents that telemedicine evaluation of nonacute headaches without performing clinical neurologic examination can be considered safe. Conversely, in some geographic areas, pathologic findings on brain CT in patients with nonacute headaches are reported almost as high as in 50\%, and possibly rendering telemedicine less safe. ${ }^{29}$

Generalizability and low risk of selection bias are strengths of this study since we consecutively recruited and consulted referred patients to a daily neurologic outpatient department. The distances to other neurologic departments and private practicing neurologists are extensive and located outside the range of the hospital's territory. Subsequently, the risk of loss to follow-up is negligible. Randomization, high response rate on the questionnaires, and thorough review of every participant's patient records are other strengths that ensure high inclusion rates and few issues with attrition.

Although we consulted all patients inside the hospital, providing similar group settings, the study design makes the study conditions less realistic. Holding the telemedicine visits within the same hospital as traditional visits clearly cuts both ways. Removing potential confounding effects of travel, location, and the use of different health care personnel strengthens the internal validity, but may also give a false feeling of security from a hospital environment in the telemedicine group. This, and the fact that the patients had to make a journey, may bring value to and build up patients' preference and satisfaction of a remote experience. Despite potential detraction from this, patients were highly satisfied in both groups, and the frequency of satisfied patients in the telemedicine group was noninferior to the traditional group. ${ }^{18}$ Lack of a placebo group and blinding are other weaknesses, but would be difficult to implement.

Although the efficacy and safety of telemedicine are comparable to traditional headache visits, the decline in HIT-6 and VAS in both groups could be caused by a deviation to the mean. ${ }^{30}$ In line with this reasoning, the efficacy of either consultation type to usual headache care has not been demonstrated. On the other hand, the results are in range of a minimal clinically important difference for HIT- 6 and beyond that of VAS. ${ }^{31-33}$ Another uncertainty is that our analyses of neuroimaging were based on radiologic descriptions from clinical practice, comprised of both CT and MRI, and did not differentiate between them. On the other hand, this reflects a real-life context in a neurologic outpatient department.

Technologies such as telemedicine are not considered neutral, but may have profound influence on history and society, and are in various degrees exposed to interpretations by users. ${ }^{34}$ The positive aspects in this study make telemedicine a compensation for the lack of headache specialists in our area. However, rules and regulations may hinder use of new technology. ${ }^{35,36}$ The fact that headaches often are underdiagnosed and suboptimally treated in general practice encourages use of telemedicine to countervail these circumstances. ${ }^{37}$

In addition to the positive long-term efficacy and safety results in this study, we have previously shown that telemedicine is an acceptable, satisfying, and feasible consultation form for nonacute headaches. ${ }^{9,18}$ Still, up to $75 \%$ of new information and communication technologies turn out to fail. ${ }^{38}$ To become successful, many examples show that such technologies ought to be built through a bottom-up procedure rather than a top-down approach. ${ }^{39,40}$ Because the foundation of our study is not built from scratch, but through a bottom-up procedure, using consulting methods and equipment already incorporated in our hospital, the chance of it becoming successfully incorporated in clinical practice is high.

Telemedicine consultation for nonacute headache is noninferior to traditional in-person clinic evaluation in respect to long-term treatment efficacy and safety, and should be a good alternative for patients 
presenting with nonacute headache. This study provides Class III evidence that a one-time telemedicine consultation for patients with nonacute headache is noninferior to a one-time traditional consultation regarding long-term treatment outcome and safety.

\section{AUTHOR CONTRIBUTIONS}

Drs. Müller and Bekkelund contributed to the conception and design, acquisition, statistical analysis, and interpretation of data. Dr. Alstadhaug contributed to conception and design and analysis and interpretation of data. All authors revised the article and approved the final version.

\section{STUDY FUNDING}

The Northern Norway Regional Health Authority (Helse Nord RHF) funded this study.

\section{DISCLOSURE}

The authors report no disclosures relevant to the manuscript. Go to Neurology.org for full disclosures.

\section{Comment: The virtual neurologist}

In 1999, Levine and Gorman ${ }^{1}$ introduced telestroke as the first major application of telemedicine to neurology. Today telestroke is standard care globally. Now, Müller et al. ${ }^{2}$ have conducted one of the largest teleneurology clinical trials for nonacute headaches.

Despite increasing interest, few randomized controlled studies of telemedicine have been conducted. In this study, over 400 nonelderly adults with nonacute headaches came to a neurology clinic in Norway and were randomized to either a traditional in-person clinical evaluation or a one-time video visit with a neurologist. The video visit consisted of a clinical history but no neurologic examination. In this noninferiority trial, no significant difference on the Headache Impact Test6 , a patient-reported outcome, was found at 12 months. The frequency of safety issues (less well-defined) appeared similar in both groups.

The study's strengths are its randomized design, large sample size, clear efficacy measures, long follow-up, and good but not complete ascertainment of study participants. The study, however, has an artificial design in which patients in both arms had to travel to a centralized clinic for evaluation. In addition, unlike telestroke, no attempt at a neurologic examination, even a screening one, was made. In practice, patients are likely to be evaluated at satellite clinics close to where they live as in the Ontario Telemedicine Network in Canada and in the Veterans Health Administration in the United States. ${ }^{3}$

Current clinical care has a fundamental flaw. It asks sick patients to travel to see healthy neurologists on their terms. As telestroke has demonstrated, technology can address this flaw by bringing a virtual neurologist to the patient. Future efforts, like those of Müller et al., ideally will extend the reach of neurologists so that almost anyone anywhere can receive neurologic care.

1. Levine SR, Gorman M. "Telestroke": the application of telemedicine for stroke. Stroke 1999;30:464-469.

2. Müller KI, Alstadhaug KB, Bekkelund SI. A randomized trial of telemedicine efficacy and safety for nonacute headaches. Neurology 2017;89:153-162.

3. Wechsler LR, Tsao JW, Levine SR, et al. Teleneurology applications: report of the Telemedicine Work Group of the American Academy of Neurology. Neurology 2013;80:670-676.

\section{E. Ray Dorsey, $M D$}

From the Department of Neurology and the Center for Health \& Technology, University of Rochester Medical Center, Rochester, NY.

Study funding: No targeted funding reported.

Disclosure: Ray Dorsey has received honoraria for speaking at American Academy of Neurology courses; compensation for consulting activities from 23andMe, Clintrex, GlaxoSmithKline, Grand Rounds, Lundbeck, MC10, MedAvante, Medico Legal services, the National Institute of Neurological Disorders and Stroke, Shire, Teva, and UCB; research support from AMC Health, Burroughs Wellcome Fund, Davis Phinney Foundation, Duke University, GlaxoSmithKline, Great Lakes Neurotechnologies, Greater Rochester Health Foundation, Huntington Study Group, Michael J. Fox Foundation, National Science Foundation, Patient-Centered Outcomes Research Institute, Prana Biotechnology, Raptor Pharmaceuticals, Roche, Safra Foundation, and University of California Irvine; and stock options from Grand Rounds. Go to Neurology.org for full disclosures.

\section{REFERENCES}

1. Rasmussen BK, Jensen R, Schroll M, Olesen J. Epidemiology of headache in a general population: a prevalence study. J Clin Epidemiol 1991;44:1147-1157.

2. Global Burden of Disease Study 2015 (GBD). Seattle: Institute for Health Metrics and Evaluation (IHME); 2015. Available at: ghdx.healthdata.org/gbd-results-tool?params $=$ querytoolpermalink/1e1e0e0f14ead39cf9d234147f456129. Accessed December 11, 2016.

3. Bekkelund SI, Albretsen C. Evaluation of referrals from general practice to a neurological department. Fam Pract 2002;19:297-299.

4. Christensen B, Silsand L, Wynn R, Ellingsen G. The Biography of Participation. Proceedings of the 13th Participatory Design Conference: Short Papers, Industry Cases, Workshop Descriptions, Doctoral Consortium Papers, and Keynote abstracts: volume 2. Windhoek, Namibia: ACM; 2014:71-74.

5. Frishberg BM, Rosenberg JH, Matchar DB, et al. Evidence-based guidelines in the primary care setting: neuroimaging in patients with nonacute headache. 2000. Available at: http://tools.aan.com/professionals/practice/ pdfs/g10088.pdf. Accessed May 31, 2017 (archived by Webcite at http://www.webcitation.org/6qs4R5iFK).

6. Detsky ME, McDonald DR, Baerlocher MO, Tomlinson GA, McCrory DC, Booth CM. Does this patient with headache have a migraine or need neuroimaging? JAMA 2006;296:1274-1283.

7. Kosinski M, Bayliss MS, Bjorner JB, et al. A six-item short-form survey for measuring headache impact: the HIT-6. Qual Life Res 2003;12:963-974.

8. Lundqvist C, Benth JS, Grande RB, Aaseth K, Russell $\mathrm{MB}$. A vertical VAS is a valid instrument for monitoring headache pain intensity. Cephalalgia 2009;29:1034-1041.

9. Müller KI, Alstadhaug KB, Bekkelund SI. Acceptability, feasibility, and cost of telemedicine for nonacute headaches: a randomized study comparing video and traditional consultations. J Med Internet Res 2016;18:e140.

10. Questback. Available at: questback.com/. Accessed April 18, 2016 (archived by WebCite at webcitation.org/6gr3li1zf).

11. The International Classification of Headache Disorders, 2nd ed. Cephalalgia 2004;24(suppl 1):9-160.

12. Davis LE, Coleman J, Harnar J, King MK. Teleneurology: successful delivery of chronic neurologic care to $354 \mathrm{pa}-$ tients living remotely in a rural state. Telemed J E Health 2014;20:473-477.

13. Honningsvåg LM, Hagen K, Haberg A, Stovner LJ, Linde M. Intracranial abnormalities and headache: a populationbased imaging study (HUNT MRI). Cephalalgia 2016;36: 113-121.

14. Sempere AP, Porta-Etessam J, Medrano V, et al. Neuroimaging in the evaluation of patients with non-acute headache. Cephalalgia 2005;25:30-35.

15. Fazekas F, Chawluk JB, Alavi A, Hurtig HI, Zimmerman RA. MR signal abnormalities at $1.5 \mathrm{~T}$ in Alzheimer's dementia and normal aging. AJR Am J Roentgenol 1987;149:351-356.

16. World Medical Association. World Medical Association Declaration of Helsinki: ethical principles for medical research involving human subjects. 2008. Available at: wma.net/en/30publications/10policies/b3/index. html. Accessed May 18, 2016 (archived by WebCite at webcitation.org/6hb61FDlz). 
17. The Norwegian Research and Management Database (FAS). Available at: forskningsprosjekter.ihelse.net/ prosjekt/HST959-10. Accessed April 12, 2016 (archived by WebCite at webcitation.org/6giJSsbSY).

18. Müller KI, Alstadhaug KB, Bekkelund SI. Telemedicine in the management of non-acute headaches: a prospective, open-labelled non-inferiority, randomised clinical trial. Cephalalgia Epub 2016 Jun 14.

19. Rubin MN, Wellik KE, Channer DD, Demaerschalk BM Role of telemedicine in providing tertiary neurological care. Curr Treat Options Neurol 2013;15:567-582.

20. Rubin MN, Wellik KE, Channer DD, Demaerschalk BM. Systematic review of teleneurology: methodology. Front Neurol 2012;3:156.

21. Chua R, Craig J, Wootton R, Patterson V. Randomised controlled trial of telemedicine for new neurological outpatient referrals. J Neurol Neurosurg Psychiatry 2001;71: 63-66.

22. Dorsey ER, Venkataraman V, Grana MJ, et al. Randomized controlled clinical trial of "virtual house calls" for Parkinson disease. JAMA Neurol 2013;70:565-570.

23. Wilkinson JR, Spindler M, Wood SM, et al. High patient satisfaction with telehealth in Parkinson disease: a randomized controlled study. Neurol Clin Pract 2016;6:241-251.

24. Ahmed SN, Mann C, Sinclair DB, et al. Feasibility of epilepsy follow-up care through telemedicine: a pilot study on the patient's perspective. Epilepsia 2008;49:573-585.

25. George BP, Scoglio NJ, Reminick JI, et al. Telemedicine in leading US neurology departments. Neurohospitalist 2012;2:123-128.

26. Yurkiewicz IR, Lappan CM, Neely ET, et al. Outcomes from a US military neurology and traumatic brain injury telemedicine program. Neurology 2012;79:1237-1243.

27. The International Classification of Headache Disorders, 3rd edition (beta version). Cephalalgia 2013;33:629-808.

28. You JJ, Gladstone J, Symons S, Rotstein D, Laupacis A, Bell CM. Patterns of care and outcomes after computed tomography scans for headache. Am J Med 2011;124:58 63.e51.

29. Imarhiagbe FA, Ogbeide E. Should non acute and recurrent headaches have neuroimaging before review by a Neurologist? A review in a Southern Nigerian Tertiary Hospital. Ann Afr Med 2011;10:290-293.

30. Goldstein LH, Seed PT, Clark LV, Dowson AJ, Jenkins LM, Ridsdale L. Predictors of outcome in patients consul- ting their general practitioners for headache: a prospective study. Psychol Health 2011;26:751-764.

31. Coeytaux RR, Kaufman JS, Chao R, Mann JD, Devellis RF. Four methods of estimating the minimal important difference score were compared to establish a clinically significant change in Headache Impact Test. J Clin Epidemiol 2006;59:374-380.

32. Hawker GA, Mian S, Kendzerska T, French M. Measures of adult pain: visual analog scale for pain (VAS pain), Numeric Rating Scale for pain (NRS pain), McGill Pain Questionnaire (MPQ), Short-Form McGill Pain Questionnaire (SF-MPQ), Chronic Pain Grade scale (CPGS), Short Form-36 Bodily pain scale (SF-36 BPS), and measure of Intermittent and Constant Osteoarthritis pain (ICOAP). Arthritis Care Res 2011;63(suppl 11): S240-S252.

33. Todd KH, Funk KG, Funk JP, Bonacci R. Clinical significance of reported changes in pain severity. Ann Emerg Med 1996;27:485-489.

34. Nicolini D. The work to make telemedicine work: a social and articulative view. Soc Sci Med 2006;62:2754-2767.

35. Wechsler LR, Tsao JW, Levine SR, et al. Teleneurology applications: report of the telemedicine work group of the American Academy of Neurology. Neurology 2013;80: 670-676.

36. Thomas L, Capistrant G. 50-State telemedicine gaps analysis: physician practice: standards \& licensure: American Telemedicine Association. 2017. Available at: americantelemed.org/ policy-page/state-telemedicine-gaps-reports. Accessed March 4, 2017 (archived by WebCite ${ }^{\circledR}$ at webcitation.org/ 6ohs7P04m).

37. Lipton RB, Scher AI, Steiner TJ, et al. Patterns of health care utilization for migraine in England and in the United States. Neurology 2003;60:441-448.

38. Berg M. Patient care information systems and health care work: a sociotechnical approach. Int J Med Inform 1999; 55:87-101.

39. Aanestad M, Jensen TB. Building nationwide information infrastructures in healthcare through modular implementation strategies. J Strateg Inf Syst 2011;20: 161-176.

40. Greenhalgh T, Morris L, Wyatt JC, Thomas G, Gunning K. Introducing a nationally shared electronic patient record: case study comparison of Scotland, England, Wales and Northern Ireland. Int J Med Inform 2013;82:e125-e138.

\section{Subspecialty Alerts by E-mail!}

Customize your online journal experience by signing up for e-mail alerts related to your subspecialty or area of interest. Access this free service by visiting Neurology.org/site/subscriptions/etoc.xhtml or click on the "E-mail Alerts" link on the home page. An extensive list of subspecialties, methods, and study design choices will be available for you to choose from-allowing you priority alerts to cutting-edge research in your field! 


\section{Neurology}

\section{A randomized trial of telemedicine efficacy and safety for nonacute headaches}

Kai I. Müller, Karl B. Alstadhaug and Svein I. Bekkelund

Neurology 2017;89;153-162 Published Online before print June 14, 2017

DOI 10.1212/WNL.0000000000004085

This information is current as of June 14, 2017

Neurology ${ }^{\circledR}$ is the official journal of the American Academy of Neurology. Published continuously since 1951, it is now a weekly with 48 issues per year. Copyright Copyright (C) 2017 The Author(s). Published by Wolters Kluwer Health, Inc. on behalf of the American Academy of Neurology. All rights reserved. Print ISSN: 0028-3878. Online ISSN: 1526-632X.

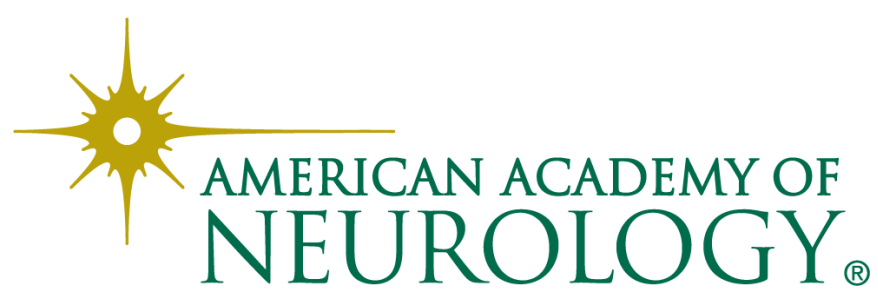




\section{Updated Information \& Services}

\section{Supplementary Material}

\section{References}

Citations

Subspecialty Collections

\section{Permissions \& Licensing}

Reprints including high resolution figures, can be found at: http://n.neurology.org/content/89/2/153.full

Supplementary material can be found at: http://n.neurology.org/content/suppl/2017/06/14/WNL.0000000000004 085.DC1

http://n.neurology.org/content/suppl/2017/06/29/WNL.0000000000004 085.DC2

This article cites 32 articles, 5 of which you can access for free at: http://n.neurology.org/content/89/2/153.full\#ref-list-1

This article has been cited by 3 HighWire-hosted articles: http://n.neurology.org/content/89/2/153.full\#\#otherarticles

This article, along with others on similar topics, appears in the following collection(s):

\section{All Headache}

http://n.neurology.org/cgi/collection/all_headache

Clinical trials Randomized controlled (CONSORT agreement)

http://n.neurology.org/cgi/collection/clinical_trials_randomized_control led_consort_agreement

Outcome research

http://n.neurology.org/cgi/collection/outcome_research

Patient safety

http://n.neurology.org/cgi/collection/patient_safety

Information about reproducing this article in parts (figures,tables) or in its entirety can be found online at:

http://www.neurology.org/about/about_the_journal\#permissions

Information about ordering reprints can be found online:

http://n.neurology.org/subscribers/advertise

Neurology ${ }^{\circledR}$ is the official journal of the American Academy of Neurology. Published continuously since 1951, it is now a weekly with 48 issues per year. Copyright Copyright ( 2017 The Author(s). Published by Wolters Kluwer Health, Inc. on behalf of the American Academy of Neurology. All rights reserved. Print ISSN: 0028-3878. Online ISSN: 1526-632X.

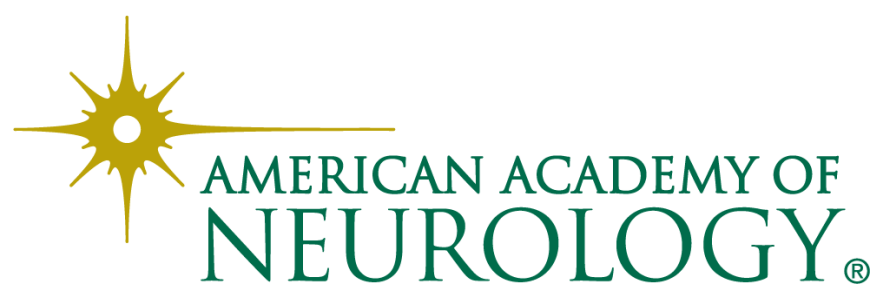

